\title{
Identification and analysis of expressed genes using a cDNA library from rat thymus during regeneration following cyclophosphamide-induced $T$ cell depletion
}

\author{
TAE-DEUK YOON ${ }^{1,2 *}$, HEE-WOO LEE ${ }^{3 *}$, YONG-SIK KIM ${ }^{4}$, HEE JUNG CHOI ${ }^{1}$, \\ JEON-OK MOON ${ }^{5}$ and SIK YOON ${ }^{1,2,6}$
}

\begin{abstract}
${ }^{1}$ Department of Anatomy; ${ }^{2}$ Medical Research Institute, Pusan National University, School of Medicine, Yangsan, Gyeongsangnam-do 626-870; ${ }^{3}$ Research Institute for Veterinary Science, College of Veterinary Medicine, Seoul National University, Seoul 151-742; ${ }^{4}$ Department of Microbiology, College of Medicine, Soonchunhyang University, Cheonan, Chungcheongnam-do 330-090; ${ }^{5}$ College of Pharmacy, Pusan National University, Busan 609 735;

${ }^{6}$ Medical Research Institute, Pusan National University Hospital, Busan 602-739, Republic of Korea
\end{abstract}

Received October 11, 2012; Accepted December 12, 2012

DOI: $10.3892 /$ ijmm.2013.1238

\begin{abstract}
Understanding the mechanisms of thymus regeneration is necessary for designing strategies to enhance host immunity when immune function is suppressed due to $\mathrm{T}$ cell depletion. In this study, expressed sequence tag (EST) analysis was performed following generation of a regenerating thymus cDNA library to identify genes expressed in thymus regeneration. A total of 1,000 ESTs were analyzed, of which $770(77 \%)$ matched to known genes, 178 matched to unknown genes (17.8\%) and $52(5.2 \%)$ did not match any known sequences. The ESTs matched to known genes were grouped into eight functional categories: gene/protein synthesis (28\%), metabolism (24\%), cell signaling and communication (17\%), cell structure and motility $(6 \%)$, cell/organism defense and homeostasis $(6 \%)$, cell division $(3 \%)$, cell death/apoptosis $(2 \%)$, and unclassified genes (14\%). Based on the data of RT-PCR analysis, the expression of TLP, E2IG2, pincher, Paip2, TGF- $\beta 1,4-1 B B$ and laminin $\alpha 3$ genes was increased during thymus regeneration. These results provide extensive molecular information, for the first time, on thymus regeneration indicating that the regenerating thymus cDNA library may be a useful source for identifying various genes expressed during thymus regeneration.
\end{abstract}

\section{Introduction}

The thymus is a pivotal central lymphoid organ that has a unique role in the development of bone-marrow-derived

Correspondence to: Professor Sik Yoon, Department of Anatomy, Pusan National University, School of Medicine, Gyeongsangnam-do, Beomeo-ri, Mulgeum-eup, Yangsan 626-870, Republic of Korea E-mail: sikyoon@pusan.ac.kr

${ }^{*}$ Contributed equally

Key words: thymus regeneration, gene expression, cDNA library, expressed sequence tag precursor cells into mature, functional $\mathrm{T}$ cells with a selfrestriction and self-tolerant mechanism. These functions of the thymus are mediated by the thymic stroma which provides a specialized microenvironment for the survival, proliferation, differentiation, and maturation of immature $\mathrm{T}$ cells. In particular, thymic epithelial cells (TECs), which form the major sub-compartment of the stroma, provide the unique combination of cellular interactions, cytokines, chemokines and various factors including thymic hormones to induce thymocyte precursors to undergo a differentiation program that leads to the generation of functional T cells (1).

The thymus gland is most prominent during early life. The thymus reaches its greatest relative weight at the time of birth, although its absolute weight continues to increase until the onset of puberty. Thereafter, the thymus begins to undergo a physiological process of involution, whereby it progressively decreases in size and the production of $\mathrm{T}$ cells progressively declines during adult life. The thymus continues to play an immunological role throughout life, although its function declines with age. Furthermore, the gradual process of physiological involution of the thymus can be acutely accelerated by acute involution or accidental involution of the thymus due to various stimuli including severe stress, ionizing radiation, adrenal and sex steroids, adrenocorticotrophic hormones, toxins, diseases such as tumors, and cytotoxic agents such as anti-neoplastic agents. In an acute involution of the thymus, the massive death of thymocytes can result in suppression of host immunity and increased susceptibility to disease. Thus, it is critical to understand the mechanisms of thymus regeneration and to thereby develop therapeutic strategies for restoring or improving host immunity when immune function is suppressed due to thymic involution.

We previously found the ultrastructural features on the hyperfunctional activities, including the high synthetic activity, in the TECs among various thymic cell types during rat thymus regeneration, thereby providing the first direct evidence that TECs, via production of several factors, are involved in the process of proliferation, maturation and differentiation of the 
$\mathrm{T}$ cell precursors during recovery from acute thymic involution (2). These facts led us to perform the present study for the identification of gene expression profiles in the thymus during its regeneration. Although some progress has been made in understanding the mechanisms of TEC-mediated thymus regeneration, they remain poorly understood (3). Most of the molecules involved in the enhancement of thymus regeneration and $\mathrm{T}$ cell reconstitution remain to be identified. Thus, identification of genes expressed during thymus regeneration is an essential step in understanding the mechanisms of thymus regeneration and in discovering new thymotrophic factors that promote thymus regeneration and $\mathrm{T}$ cell reconstitution.

A number of techniques, such as differential display, subtractive hybridization, SAGE (serial analysis of gene expression) and gene arrays, have been developed for the identification of genes that are specifically expressed in a particular cell, tissue, organ or organism, or are differentially expressed under varying conditions such as development, differentiation, activation, stimulation, environmental changes and disease, over the last several decades. The expressed sequence tag (EST) is short single-pass sequence reads of randomly selected clones from cDNA libraries (4). The EST approach is also an effective technology for characterizing genes expressed during various biological processes since ESTs provide a reliable method for gene discovery as well as a resource for the large-scale analysis of gene expression of known and unknown genes. A cDNA library is constructed from total RNA or poly(A) RNA derived from specific tissues or cells, and represents genes expressed in the original cellular population. Therefore, ESTs have been shown to be a powerful tool in identifying homologues of reported genes and gene expression in tissues or cells $(5,6)$. The discovery of novel or known genes expressed in thymus regeneration and the determination of their expression patterns in the thymus during regeneration will help elucidate their roles in thymus regeneration and will provide the basis for the development of effective therapeutic strategies for promoting thymus regeneration. Thus, in this study, EST analysis was performed following generation of the regenerating thymus cDNA library and the expressed genes were compiled to identify genes expressed during thymus regeneration.

\section{Materials and methods}

Experimental acute thymic involution and regeneration model. Adult male specific pathogen-free Sprague-Dawley rats were purchased from Dae Han Bio Link (Seoul, Korea). All rats were housed 3-4/cage and maintained under a $12 \mathrm{~h} \mathrm{light/dark} \mathrm{cycle}$ at $24^{\circ} \mathrm{C}$ in a specific pathogen-free and humidity-controlled facility. Animals were provided with standard sterile food and water ad libitum, and were allowed to adjust to their environment for one week. Animals were used at 8-10 weeks of age, by administering them with a single intraperitoneal dose of cyclophosphamide $(150 \mathrm{mg} / \mathrm{kg}$ body weight; Sigma, St. Louis, MO, USA) in normal saline, and were sacrificed in groups of six at 3 and 7 days, for the construction of the cDNA library, or in groups of four at 3,7 and 14 days after injection, for RT-PCR analysis. Rats given the same amount of normal saline were used as controls. Animal care and all experimental procedures were conducted in accordance with the 'Guide for Animal Experiments' edited by the Korean Academy of Medical Sciences.

cDNA library construction and EST sequencing. Total RNA was extracted from regenerating thymus 3 and 7 days after cyclophosphamide treatment using total RNA isolation kit (CPG, Inc., Lincoln Park, NJ, USA), following the manufacturer's instructions. Poly(A) RNA was purified from the total RNA using mRNA extraction kit (Stratagene, La Jolla, CA, USA). Briefly, $5 \mathrm{mg}$ of total RNA was mixed with $5 \mathrm{ml}$ of elution buffer and was then hybridized to $0.2 \mathrm{~g}$ of oligo(dT) cellulose at room temperature with gentle agitation, followed by high-salt (low-stringency) and low-salt (high-stringency) washes. These washes removed unwanted components of the crude lysate, such as proteins, carbohydrates, lipids, DNA, transfer RNA (tRNA) and a significant amount of ribosomal RNA (rRNA) from poly(A) mRNA. The oligo(dT) cellulose was loaded onto a push column, and mRNA was eluted with $65^{\circ} \mathrm{C}$ elution buffer. The mRNA was concentrated by ethanol precipitation. The mRNA concentration was determined by absorbance at $260 \mathrm{~nm}$.

Directionally cloned (EcoRI/XhoI) cDNA libraries were generated from poly(A) RNA using a $\lambda$-Uni-Zap-XR cDNA synthesis kit (Stratagene) and ZAP-cDNA Gigapack III Gold cloning kit (Stratagene) according to the manufacturer's instructions. For all libraries, individual white colonies were inoculated in LB broth containing ampicillin $(100 \mu \mathrm{g} / \mathrm{ml})$ and were incubated for $12 \mathrm{~h}$. Double-stranded plasmid DNA from individual cDNA clones was isolated with a Qiagen plasmid DNA preparation kit (Qiagen, Valencia, CA, USA). The titer of the unamplified library was $1.2 \times 10^{6} \mathrm{pfu} / \mathrm{ml}$ and average insert size was $\sim 0.8-2.5 \mathrm{~kb}$. Individual clones were randomly selected for plasmid DNA purification and were sequenced by Macrogen Inc. (Seoul, Korea).

Thymocytes and thymic stromal cell isolation. Two to three thymi were dissected from freshly sacrificed rats and trimmed of fat and connective tissue. Small cuts $(2-3 \mathrm{~mm})$ were made into the capsules with a pair of razors, and thymi were gently agitated in $30 \mathrm{ml}$ of RPMI-1640 using a magnetic stirrer at $4^{\circ} \mathrm{C}$ for $40 \mathrm{~min}$. The resulting thymic fragments and supernatants were transferred into separate tubes. For the isolation of thymocytes, the supernatant was passed three times through $70 \mu \mathrm{m}$ mesh and centrifuged. The cell pellet was resuspended in $20 \mathrm{ml}$ of ACK lysis solution $\left(0.15 \mathrm{M} \mathrm{NH}_{4} \mathrm{Cl}, 1 \mathrm{mM} \mathrm{KHCO}_{3}\right.$ and $0.1 \mathrm{mM} \mathrm{Na}_{2}$ EDTA) to remove red blood cells. The thymocyte suspension was washed three times with HBSS buffer. The thymocytes were then resuspended in HBSS buffer, and viable cells were counted using the hemocytometer following trypan blue staining.

For the isolation of thymic stromal cells, the thymic fragments were transferred into $5 \mathrm{ml}$ of RPMI-1640 containing $0.125 \%$ (w/v) collagenase D and 0.1\% (w/v) DNase I (both from Roche Diagnostics GmbH, Mannheim, Germany) and were then incubated for $15 \mathrm{~min}$ with gentle shaking in a water bath at $37^{\circ} \mathrm{C}$. The thymic fragments in the enzyme mixtures were carefully dispersed with a Pasteur pipette several times, and the supernatant was removed after fragments had settled, and replaced with fresh enzyme mixture. Gentle mechanical agitation was provided using a $5 \mathrm{ml}$ syringe and $18 \mathrm{G}$ needle, 


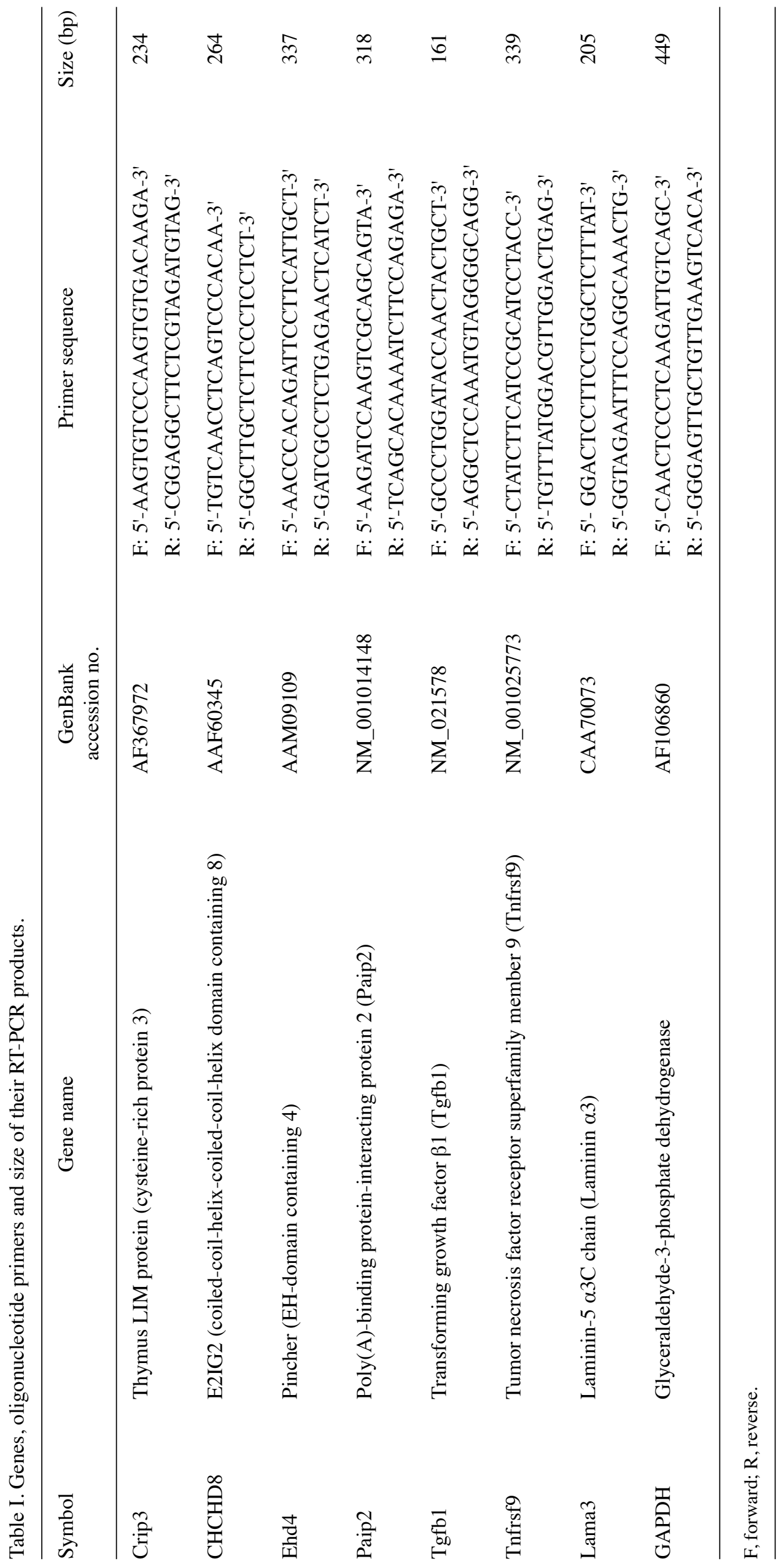


Table II. Results of EST sequences for regenerating rat thymus cDNA library.

\begin{tabular}{lrc}
\hline Library & $\begin{array}{c}\text { No. of } \\
\text { clones }\end{array}$ & $\begin{array}{c}\text { Percentage } \\
(\%)\end{array}$ \\
\hline Total number of gene cluster & 1,000 & 100 \\
Known genes & 770 & 77 \\
Unknown genes & 178 & 17.8 \\
Unidentified genes & 52 & 5.2 \\
\hline
\end{tabular}

then a $21 \mathrm{G}$ needle followed by a $23 \mathrm{G}$ needle. Tissue fragments were allowed to settle and the supernatant was discarded. This digestion process was repeated four more times until the tissue was fully digested. Cells liberated by the fourth, fifth and sixth digests were saved, filtered through a $100 \mu \mathrm{m}$ mesh to remove undigested particles, and washed three times with HBSS buffer. They were then resuspended in HBSS buffer, and viable cells were counted using the hemocytometer following trypan blue staining.

Reverse transcriptase-polymerase chain reaction (RT-PCR). Total RNA was isolated from Easy-Blue RNA Extraction Reagent (Intron, Seoul, Korea) following the manufacturer's protocol. First strand cDNA was obtained by reverse transcription (RT) using $2 \mu \mathrm{g}$ of total RNA. The reaction was conducted in $20 \mu \mathrm{l}$ of buffer containing $0.5 \mu \mathrm{g}$ of Oligo(dT) $)_{12-18}$ primer, $50 \mathrm{mM}$ Tris- $\mathrm{HCl}$ (pH 8.3), $75 \mathrm{mM} \mathrm{KCl}, 3 \mathrm{mM} \mathrm{MgCl} 2,40 \mathrm{mM}$ DTT, $0.5 \mathrm{mM}$ deoxynucleotide triphosphate (dNTP) mixture, 10 units of RNAse inhibitor, and 200 units of M-MLV reverse transcriptase (Gibco-BRL). Following incubation at $37^{\circ} \mathrm{C}$ for $60 \mathrm{~min}$, the reaction was stopped by heating at $70^{\circ} \mathrm{C}$ for $15 \mathrm{~min}$. To remove the remaining RNA, $1 \mu 1$ of $E$. coli RNase H $(4 \mathrm{mg} / \mathrm{ml})$ was added to the reaction mixture and incubated at $37^{\circ} \mathrm{C}$ for $30 \mathrm{~min}$. The cDNA was used as a template for PCR amplification using gene-specific primers (Table I). PCR amplification of the cDNA was performed in an automated thermal cycler (Techne, Teddington, UK) in a final volume of $25 \mu 1$ containing $4 \mu \mathrm{l}$ of cDNA solution, $20 \mathrm{mM}$ Tris- $\mathrm{HCl}$ (pH 8.4), $50 \mathrm{mM} \mathrm{KCl}, 1.5 \mathrm{mM} \mathrm{MgCl}_{2}, 0.1 \%$ Triton X-100, $0.2 \mathrm{mM}$ dNTP mixture (Gibco-BRL), 0.5 pmol of each primer and 5 units of TaqDNA polymerase (Promega, Madison, WI, USA). The amplification included an initial denaturation at $94^{\circ} \mathrm{C}$ for $5 \mathrm{~min}$ and then 25 or 30 cycles of denaturation at $94^{\circ} \mathrm{C}$ for $30 \mathrm{sec}$, primer annealing at $55^{\circ} \mathrm{C}$ for $30 \mathrm{sec}$, and extension at $72^{\circ} \mathrm{C}$ for $30 \mathrm{sec}$, followed by a final extension at $72^{\circ} \mathrm{C}$ for $10 \mathrm{~min}$, ending with a $4^{\circ} \mathrm{C}$ hold cycle. After the PCR, the amplified products were analyzed by electrophoresis in $1.5 \%$ agarose gel and visualized by ethidium bromide staining under UV light illumination. Band intensities of the PCR products were measured and plotted using an image analysis program (MetaMorph; Universal Imaging Corporation, Downingtown, PA, USA).

Statistical analysis. Data are expressed as the means \pm SD for each condition. For comparison of multiple groups, a one-way analysis of variance (ANOVA) followed by a Scheffe's post hoc test was performed. $\mathrm{P}<0.05$ was considered to indicate a statistically significant difference.

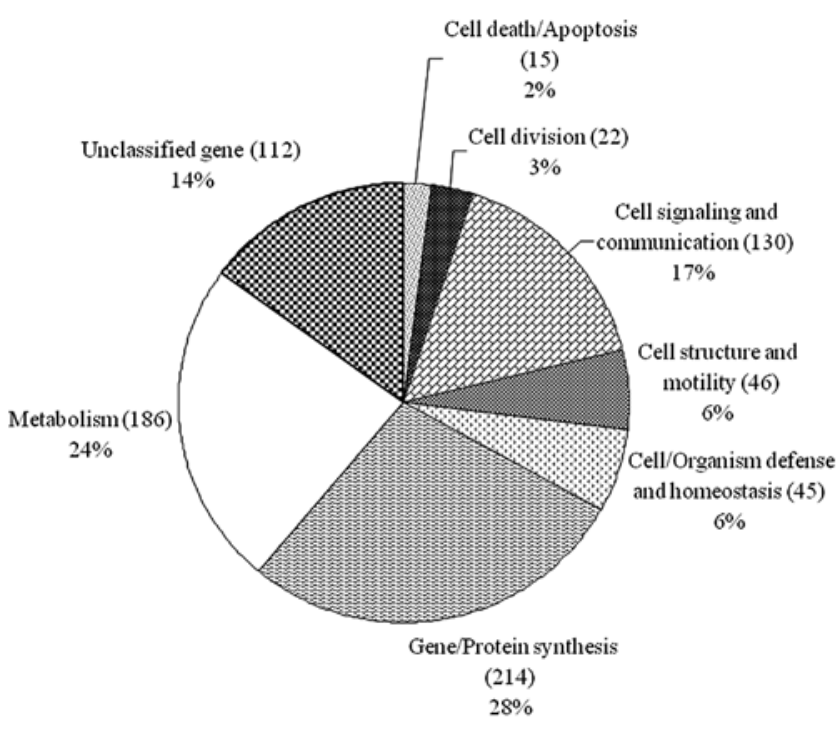

Figure 1. Functional classification of proteins encoded by the cDNAs of the ESTs matched to known genes. The deduced proteins were grouped into 8 functional categories based on sequence similarity with proteins of known function. The fraction of the ESTs corresponding to the respective category is indicated.

\section{Results}

The regenerating thymus cDNA library was generated by unidirectional insertion of oligo-dT-primed cDNAs into $\lambda$-ZAP-Express. The phage library was converted through mass excision to a plasmid library in the vector pBluescript II. The regenerating thymus cDNA library contained $\sim 2.18 \times 10^{10} \mathrm{pfu}$. The identities of cloned sequences were determined by a BLAST search of publicly available databases. The insert size was distributed in a range from 0.8 to $2.5 \mathrm{~kb}$. A total of 1,080 randomly selected clones from the regenerating thymus library were sequenced. Each sequence was then aligned with all other EST sequences in non-redundant nucleotide (NR) and dbEST databases of NCBI using the BLASTN (BLAST nucleotide) program (www.ncbi.nlm. nih.gov/BLAST). In this study, E-value scores $<1.0 \mathrm{e}^{-5}$ were considered to be significant.

The average length of readable sequence was $\sim 400$ nucleotides. Of the 1,080 clones, 1,000 were sequenced clones and 80 were read-fail clones. Of the 1,000 ESTs, 770 displayed similarity to previously described genes with a BLASTN E-value of $\leq 1.0 \mathrm{e}^{-5}$, representing known genes. A total of 1,000 ESTs were analyzed, of which 770 (77\%) matched to known genes, 178 matched to unknown genes (17.8\%) and $52(5.2 \%)$ did not match any known sequences (Table II).

The library complexity (i.e., the total number of different sequences in the library) was estimated by NCBI search on the basis of the 770 ESTs from the regenerating thymus cDNA library. Among the 770 ESTs, 611 were found only once (87.3\%) without counting similar sequences in collected ESTs. The other 159 revealed more than two overlapping sequences.

Most abundant clones in the regenerating thymus cDNA library were identified and listed in Table III. Highly abundant ESTs were 107 (17.5\%) and sequenced more than four times. The EST which showed the highest frequency was asparaginase-like 1 (L-asparaginase), which occurred 10 times. 
Table III. Most abundant cDNA clones in the regenerating rat thymus cDNA library.

\begin{tabular}{|c|c|c|c|c|}
\hline \multirow[b]{2}{*}{ Rank } & \multicolumn{2}{|r|}{ Putative identification } & \multirow[b]{2}{*}{$\begin{array}{l}\text { GenBank } \\
\text { accession no. }\end{array}$} & \multirow[b]{2}{*}{$\begin{array}{l}\text { No. of } \\
\text { ESTs }\end{array}$} \\
\hline & Symbol & Gene name & & \\
\hline 1 & Asrgl1 & Asparaginase like 1 (Asrgl1) & NM_145089 & 10 \\
\hline 2 & Eef1a1 & Eukaryotic translation elongation factor $1 \alpha 1$ (Eef1a1) & NM_175838 & 9 \\
\hline 3 & Slc25a4 & Adenine nucleotide translocator (Solute carrier family 25 ) & CAA43842 & 8 \\
\hline 4 & Bcas1 & $\begin{array}{l}\text { Breast carcinoma-amplified sequence } 1 \text { homolog isoform } 1 \\
\text { (breast carcinoma amplified sequence 1) }\end{array}$ & NP_084091 & 6 \\
\hline 5 & Tmsb4x & Thymosin $\beta 4$ & NP_112398 & 6 \\
\hline 6 & Hspa9 & Stress-70 protein, mitochondrial [heat shock $70 \mathrm{kDa}$ protein 9 (mortalin)] & NP_034611 & 5 \\
\hline 7 & Ccng1 & Cyclin G & CAA50219 & 5 \\
\hline 7 & Arpp21 & $\begin{array}{l}\text { Cyclic AMP-regulated phosphoprotein } \\
\text { (cAMP-regulated phosphoprotein, } 21 \mathrm{kDa} \text { ) }\end{array}$ & ВC089974 & 5 \\
\hline 10 & $\mathrm{Cd} 74$ & Cd74 molecule, major histocompatibility complex, class II invariant chain & ВC059152 & 5 \\
\hline 10 & Apoe & Apolipoprotein E & ВC060313 & 4 \\
\hline 10 & Rnf111 & Arkadia (ring finger protein 111) & AAK38272 & 4 \\
\hline 10 & Naip2 & Baculoviral IAP repeat-containing $1 \mathrm{~b}$ & AAN77613 & 4 \\
\hline 10 & $\operatorname{Tm} 2 \mathrm{~d} 2$ & TM2 domain containing 2 & ВC093382 & 4 \\
\hline 10 & mt-COI & Cytochrome-c oxidase I & CAA32956 & 4 \\
\hline 10 & Dhfr & Dihydrofolate reductase & NP_034179 & 4 \\
\hline 10 & Pira6 & Immunoglobulin-like receptor PIRA6 (12M1) & U96687 & 4 \\
\hline 10 & Usp33 & Ubiquitin specific peptidase 33 & ВC092624 & 4 \\
\hline 10 & Rps3a & Ribosomal protein S3a & AAH58483 & 4 \\
\hline 10 & Sf3b2 & Unnamed protein product (splicing factor $3 \mathrm{~b}$, subunit $2,145 \mathrm{kDa}$ ) & BAC32755 & 4 \\
\hline 10 & Mtf2 & $\begin{array}{l}\text { Metal-response element-binding transcription factor } 2 \text { isoform } 1 \\
\text { (Metal-response element-binding transcription factor 2) }\end{array}$ & NP_038855 & 4 \\
\hline 10 & Tob2 & Tob2 protein (transducer of ERBB2, 2) & AAH11163 & 4 \\
\hline
\end{tabular}

The 770 ESTs matched to known genes were grouped into eight functional categories based on the TIGR gene cellular directory (http://www.tigr.org) (Fig. 1). Among the 770 ESTs, $214(28 \%)$ were gene or protein synthesis related genes, 186 (24\%) were metabolism related genes, 130 (17\%) were cell signaling and communication related genes, $46(6 \%)$ were cell structure and motility related genes, $45(6 \%)$ were cell/organism defense and homeostasis related genes, 22 (3\%) were cell division related genes, $15(2 \%)$ were cell death/apoptosis related genes, and, finally, 112 (14\%) were unclassified genes (Fig. 1).

Seven genes that may be involved in thymus regeneration were selected based on their biological function rather than the frequency, and the gene expression was analyzed in thymocytes and thymic stromal cells isolated from normal and regenerating rat thymus using RT-PCR analysis. The seven genes were: thymus LIM protein (TLP, cysteine-rich protein 3), estradiol-induced gene 2 (E2IG2), pincher (pinocytic chaperone), poly(A) binding protein interacting protein 2 (polyadenylate-binding protein-interacting protein 2, Paip2), transforming growth factor- $\beta 1$ (TGF- $\beta 1)$, tumor necrosis factor receptor superfamily member 9 (4-1BB, Tnfrsf9) and laminin $\alpha 3$ (laminin-5 $\alpha 3$ ). Based on the data of RT-PCR analysis, the expression of TLP, E2IG2, pincher, Paip2, TGF- $\beta 1$, $4-1 \mathrm{BB}$ and laminin $\alpha 3$ was increased in both the thymocytes and thymic stromal cells during thymic regeneration, particularly 3 and 7 days after cyclophosphamide treatment (Fig. 2A-G).

\section{Discussion}

In our previous studies, we established an experimental thymus regeneration model to investigate the mechanisms underlying $\mathrm{T}$ cell regeneration (2,7-10). Using this model, in the present study, we analyzed several genes that may be related to $\mathrm{T}$ cell regeneration from a regenerating rat thymus cDNA library. Of note, our data showed an upregulated expression of genes related to a translational machinery, as inferred by the expression of protein synthesis-related genes (28\%), indicating the effectiveness of our experiment, since the regulation of gene expression at the translational level plays a key role in the 
A
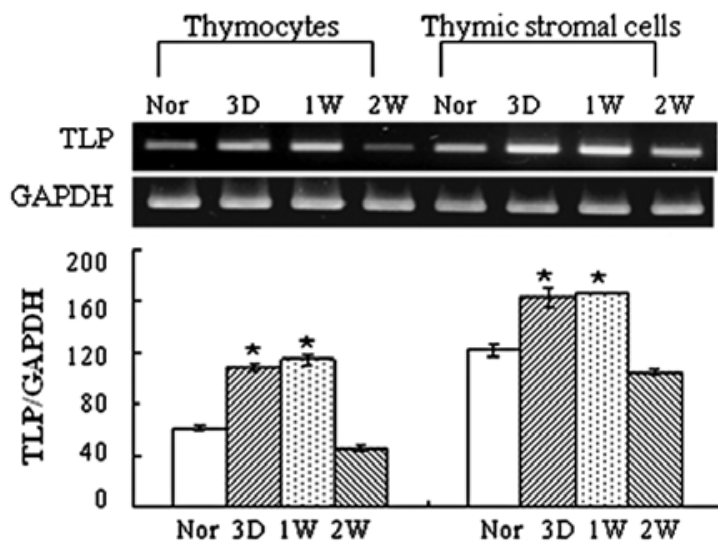

C
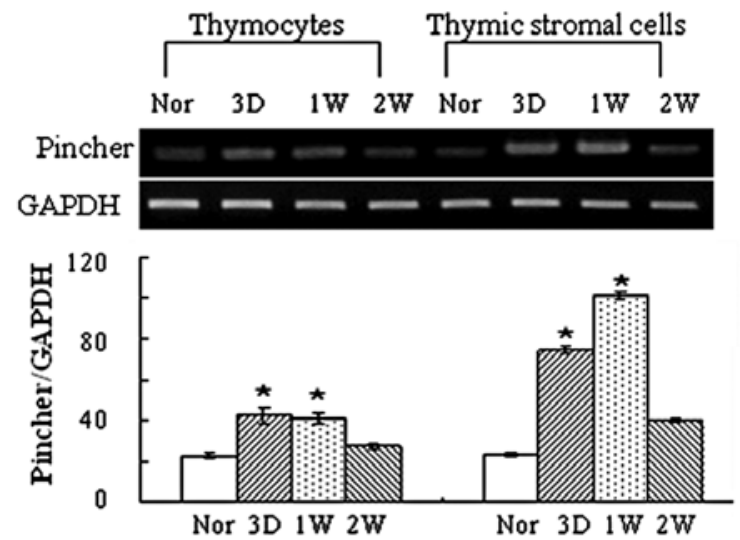

E

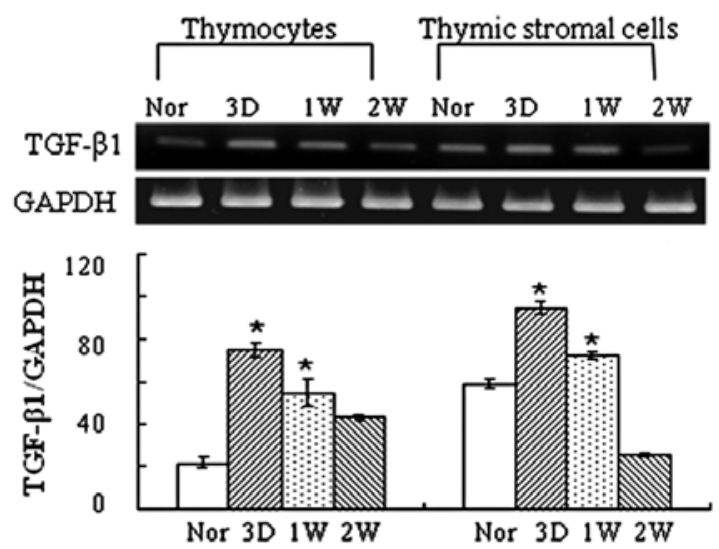

B

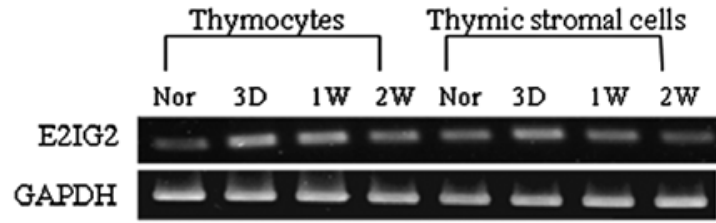

D
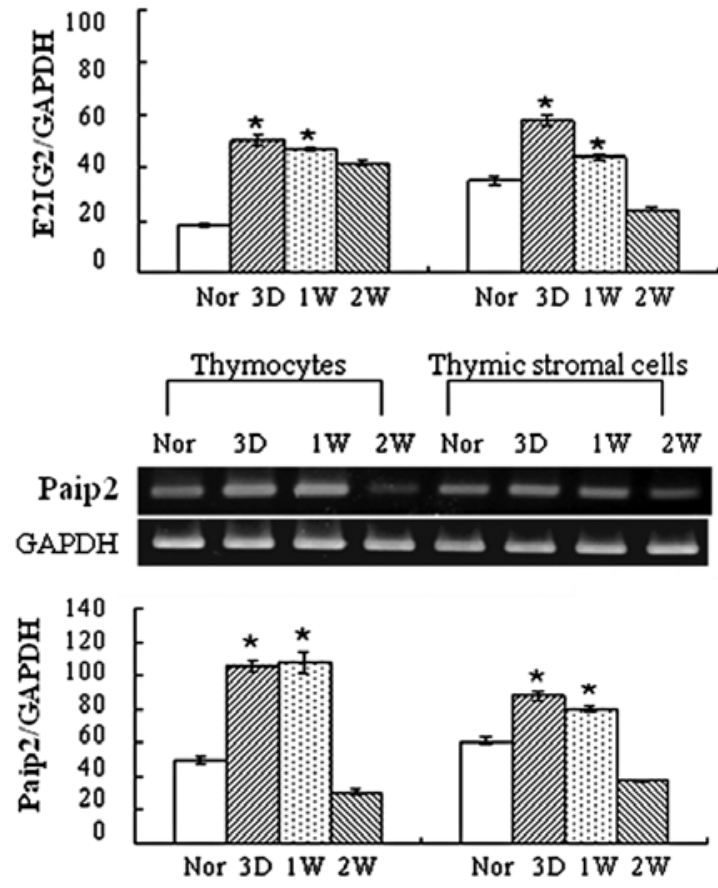

F
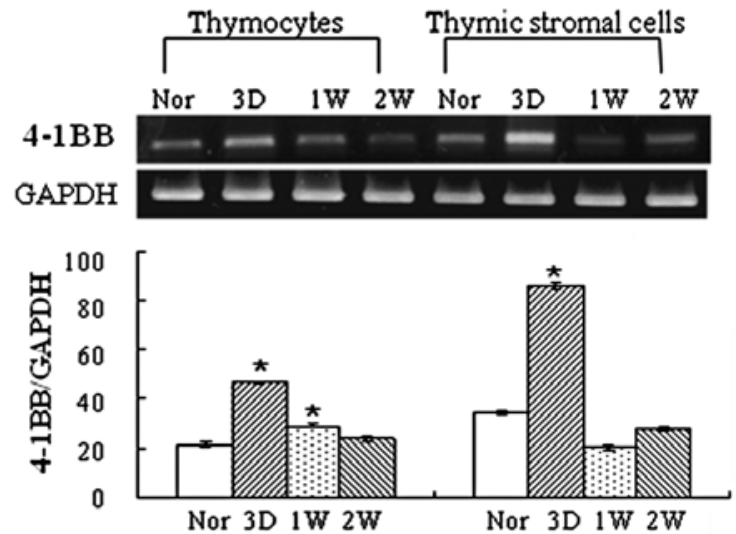

G

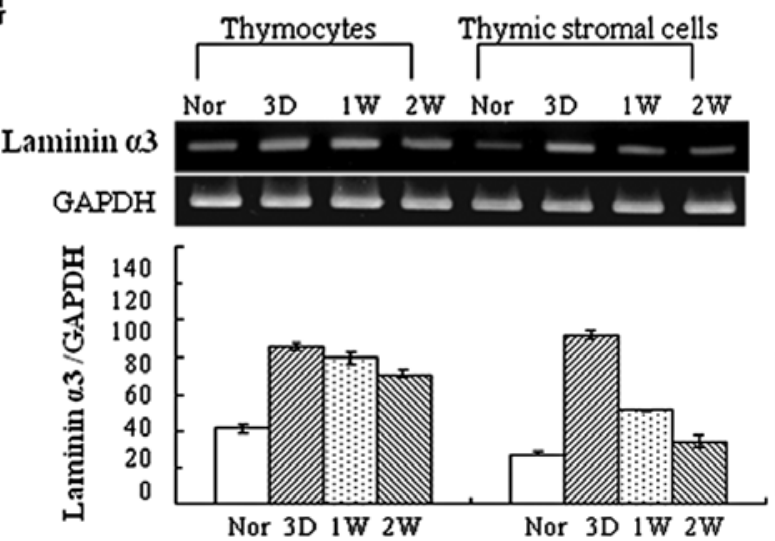

Figure 2. RT-PCR analysis of (A) TLP, (B) E2IG2, (C) pincher, (D) Paip2, (E) TGF- $\beta 1$, (F) 4-1BB and (G) laminin $\alpha 3$ mRNA in the thymic stromal cells and thymocytes of normal rats (Nor), and 3 (3D), 7 (1W) and $14(2 \mathrm{~W})$ days after cyclophosphamide treatment. The images show the representative agarose gel electrophoresis of the RT-PCR products for each gene co-amplified with GAPDH. The density of each band in each lane was quantitated by scanning densitometry and then expressed as the mean $\pm \mathrm{SD} .{ }^{*} \mathrm{P}<0.05$ compared with the corresponding control value, as determined by a one-way analysis of variance (ANOVA) followed by a Scheffe's post hoc test. 
induction of quiescent $\mathrm{T}$ cells to re-enter the cell cycle and proliferate, which is a necessary step of cellular regeneration.

Of particular interest, among genes expressed in the regenerating rat thymus, we identified the seven genes which may be involved in thymus regeneration. LIM domain proteins are known to play a number of important roles in the development and differentiation of normal as well as of cancer cells $(11,12)$. In particular, it has been reported that LIM domain proteins, in association with TAL1 (T-cell acute leukaemia 1)/SCL (stem cell leukaemia), cause arrest of thymocyte differentiation at the $\mathrm{CD}^{-} \mathrm{CD} 8-\mathrm{DN}$ to $\mathrm{CD}^{+}{ }^{+} \mathrm{CD} 8^{+} \mathrm{DP}$ transition (13). A novel LIM gene encoding TLP expressed specifically in the thymus in a subset of cortical epithelial cells near the corticomedullary junction (14). It was shown that TLP is upregulated in a thymus in which selection of $\mathrm{T}$ cells is occurring ( $\mathrm{Rag}^{-/} \mathrm{OT}-1$ mice) compared to its expression in a thymus in which selection is blocked at the $\mathrm{CD} 4^{+} \mathrm{CD} 8^{+} \mathrm{DP}$ stage of $\mathrm{T}$ cell development $\left(\mathrm{Rag}^{-/} \mathrm{Tap}^{-/}\right.$OT-1 mice) (14). They also suggested that TLP may have a role in thymus development by demonstrating that targeted disruption of TLP results in a reduction of thymus cellularity by approximately $30 \%$, with a proportional reduction in each subpopulation (14). Furthermore, accumulating evidence suggests that LIM domain proteins play a crucial role in hematopoiesis (15-18). These facts, together with our experimental findings, indicate a novel role of TLP in thymus regeneration.

It has been established that sex hormones influence lymphocyte development and, in particular, high levels of estrogen, as in the case of pregnancy or estrogen administration, can induce profound thymic atrophy and result in immunosuppressive effects on the peripheral immune systems, whereas estrogen deficiency, as in the case of ovariectomy, induces significant enlargement of the thymus (19). In line with this action of estrogen on the thymus, it is noteworthy that the gene expression of E2IG2, a member of novel genes upregulated by estrogen treatment and first identified by serial analysis of gene expression in estrogen-responsive breast cancer cells following exposure to this hormone, was upregulated during thymus regeneration in the present study, suggesting its potential role in the process of postnatal $\mathrm{T}$ cell development and production (20). However, the function of E2IG2 remains unclear.

It was observed that thymic cells are able to produce nerve growth factor (NGF) protein and mRNA (8). In particular, we have shown that the expression of NGF and its high affinity receptor TrkA are upregulated in the rat TECs during thymus regeneration following acute thymic involution $(7,8)$. Furthermore, we have shown that NGF induces upregulation of a unique potent angiogenic factor, vascular endothelial growth factor (VEGF) in TECs, which may play a key role in the reparative angiogenesis during thymus regeneration (9). NGF also stimulates TEC activities including cell proliferation, thymocyte adhesion to TECs, the expression of critical cell adhesion molecules such as intercellular adhesion molecule-1 (ICAM-1) and vascular cell adhesion molecule-1 (VCAM-1), which mediate thymocyte-TEC interactions and the production of major thymopoietic factors including interleukin (IL)-7, granulocyte-macrophage colony-stimulating factor (GM-CSF), stromal cell-derived factor-1 (SDF-1), thymus and activation-regulated chemokine (TARC) and thymusexpressed chemokine (TECK) (21). These data collectively suggest that NGF, particularly on TECs, may play a role in the $\mathrm{T}$ lymphopoiesis associated with thymus regeneration during recovery from acute thymic involution.

Pincher, an NGF-induced protein, functions in endocytosis and trafficking of NGF and its receptor TrkA functions as a pinocytic chaperone for vesicles containing these molecules (22). Pincher function is necessary for both the NGF-induced internalization of TrkA by a pinocytic process, and the sorting of long-lived endosomal vesicles with NGF signaling capability (22). Pincher-mediated macroendocytosis for NGF generates Trk endosomes that are refractory to lysosomal processing, thus ensuring sustained endosomal signaling after retrograde transport, which is crucial for regulating neuronal phenotype and survival $(23,24)$. Thus, these results indicate that pincher mediates pinocytic endocytosis of NGF and TrkA which play an important role in the processes of thymus regeneration.

The cap structure and the poly(A) tail of eukaryotic mRNAs act synergistically to enhance translation. This effect is mediated by a direct interaction of eukaryotic initiation factor $4 \mathrm{G}\left(\mathrm{eIF}_{4} \mathrm{G}\right)$ and poly(A) binding protein (Pabp), which results in circularization of the mRNA. Of the two identified Pabp-interacting proteins (Paip), one, Paip1, stimulates translation through its interaction with eukaryotic initiation factor 3 $\left(\mathrm{IF}_{3}\right)(25)$, and the other, Paip2, which competes with Paip1 for binding to Pabp, represses translation by competing with $\mathrm{eIF}_{4} \mathrm{G}$ for Pabp binding and by decreasing the affinity of Pabp for the poly(A) tail $(26,27)$. Two isoforms of Paip2, Paip2a and Paip2b, have been defined in mammals and are expressed differentially in tissues, indicating tissue-specific functions and responses to distinct stimuli $(28,29)$. In a previous study, we showed that the expression of VEGF is upregulated during thymus regeneration following thymic involution induced by cyclophosphamide treatment (9). Thus, it is hypothesized that Paip2 could modulate thymus regeneration by upregulating VEGF expression. Further studies on Paip2 in thymus regeneration could provide important information about its role in the postnatal $\mathrm{T}$ cell development.

TGF- $\beta 1$ may have a broad function not only for $\mathrm{T}$ cell selection and death in immune responses and in the generation of tolerance, but also for defining the mechanisms of programmed cell death in general (30). It has been demonstrated that TGF- $\beta 1$ regulates the gene expression of atrial natriuretic peptide (ANP) receptors in the thymic stromal cells and that ANP and TGF- $\beta 1$ may affect the thymic stromal cell functions (31). Markedly, it was demonstrated that TGF- $\beta 1$ signaling in TECs accelerates the process of age-related thymic involution and transiently hinders the early phase of thymic reconstitution after myeloablative conditioning and hematopoietic stem cell transplantation, suggesting that the pharmacological inhibition of TGF- $\beta 1$ activity could constitute a novel component of a conditioning regimen to hasten thymopoietic activity following hematopoietic stem cell transplantation (32).

4-1BB, a member of the TNFR superfamily, is a major costimulatory receptor that is rapidly expressed on the surface of $\mathrm{CD}^{+}$and $\mathrm{CD} 8^{+} \mathrm{T}$ cells after antigen- or mitogen-induced activation. Costimulation through 4-1BB by either 4-1BBL or agonistic monoclonal antibodies (mAbs) enhances $\mathrm{T}$ cell activity (33) and promotes $\mathrm{CD} 8^{+} \mathrm{T}$ cell survival (34). We have demonstrated that the expression of $4-1 \mathrm{BB}$ and $4-1 \mathrm{BBL}$ is preferentially expressed in the regenerating thymus, mainly 
in $\mathrm{CD}^{+} \mathrm{CD} 8^{+}$double-positive (DP) thymocytes (10). The 4-1BB and 4-1BBL positive cells among the $\mathrm{CD} 4^{+} \mathrm{CD} 8^{+} \mathrm{DP}$ thymocytes present during thymus regeneration were $\mathrm{TCR}^{\mathrm{h}}$ and $\mathrm{CD} 9^{+}$, unlike the corresponding controls, indicating that 4-1BB and 4-1BBL are predominantly expressed by the positively selected population of the $\mathrm{CD} 4^{+} \mathrm{CD} 8^{+} \mathrm{DP}$ during thymus regeneration (10). We also found that the interaction of 4-1BB with 4-1BBL promoted thymocyte adhesion to TECs and suggested that 4-1BB and 4-1BBL are involved in T lymphopoiesis associated with positive selection during recovery from acute thymic involution (10).

Laminin $\alpha 3$ regulates various cellular functions, including cell adhesion and migration (35). It has been found that laminin $\alpha 3$ chain plays a role in $\mathrm{T}$ cell development (36). However, much remains to be clarified regarding the role of laminin $\alpha 3$ chain in thymus function.

Among the most frequently expressed genes during thymus regeneration, L-asparaginase, adenine nucleotide translocator and thymosin $\beta 4$ were striking. L-asparaginase, first cloned as asparaginase-like sperm autoantigen from rat and human testis cDNA libraries on the basis of reactivity with antibodies produced after vasectomy, was found to be expressed not only in the testis but also in the heart, brain, liver, skeletal muscle and kidney (37). It has been shown that loss of the eukaryotic initiation factor $2\left(\mathrm{eIF}_{2}\right)$ kinase, general control nonderepressible kinase $2(\mathrm{GCN} 2)$ function renders the immune system more sensitive to the cytotoxic effects of asparaginasemediated amino acid deprivation, leading to enhanced cell death of lymphocytes $(38,39)$. This finding provides insight into the role of GCN2 in the immunosuppression caused by asparaginase. Thus, it is conceivable that $\mathrm{L}$-asparaginase that exists in high frequency in the ESTs of regenerating rat thymus may be involved in thymic involution by potentiating cyclophosphamide-induced thymocyte depletion possibly via its action on GCN2.

Adenine nucleotide translocator serves as a component of the mitochondrial permeability transition pore complex, and plays a major role in promoting mitochondria-mediated apoptosis (40). It has been demonstrated that mitochondrial adenine nucleotide translocator 3 is regulated by IL- 4 and IFN- $\gamma$ via STAT-dependent pathways, and regulation of mitochondrial adenine nucleotide translocator 3 by IL-4 may have a functional implication in cytokine-mediated T cell survival (41,42); however, the role of adenine nucleotide translocator during thymus regeneration remains to be investigated.

Thymosin $\beta 4$, a small 43 -amino acid polypeptide that was first isolated from calf thymus, enhances cell migration and adhesion, promotes angiogenesis and cell differentiation, prevents apoptosis, promotes cell survival and tissue regeneration, and enhances wound healing and repair (43). In particular, thymosin $\beta 4$ acts on lymphoid stem cells and controls the early stages of the maturation process of thymus-dependent lymphocytes (44). Abundant expression of this gene in the ESTs of regenerating rat thymus suggests that it may be significantly involved in the thymus during regeneration.

Collectively, we have compiled genes expressed in the regenerating thymus and identified specific genes which may be involved in the processes of rat thymus regeneration, thereby providing new comprehensive molecular information on thymus regeneration for the first time. The regenerating thymus cDNA library constructed in this study may be a useful source for identifying various genes expressed during thymus regeneration. Therefore, the present study provides further insight into the development of novel therapeutic strategies for effective thymus repopulation in the design of therapies for numerous clinical conditions in which immune reconstitution is required.

\section{Acknowledgements}

This study was supported by the Medical Research Institute Grant (2004-37), Pusan National University Hospital, and the National Research Foundation of Korea (NRF) Grant funded by the Korean government (MEST) (no. 2010-0014194).

\section{References}

1. Ritter MA and Palmer DB: The human thymic microenvironment: new approaches to functional analysis. Semin Immunol 11: 13-21, 1999.

2. Yoon S, Yoo YH, Kim BS and Kim JJ: Ultrastructural alterations of the cortical epithelial cells of the rat thymus after cyclophosphamide treatment. Histol Histopathol 12: 401-413, 1997.

3. Toubert A, Glauzy S, Douay C and Clave E: Thymus and immune reconstitution after allogeneic hematopoietic stem cell transplantation in humans: never say never again. Tissue Antigens 79: 83-89, 2012.

4. Gutierrez JA: Genomics: from novel genes to new therapeutics in parasitology. Int J Parasitol 30: 247-252, 2000.

5. Shiue YL, Wang LH, Chao TY, Lin CH and Tsai CL: EST-based identification of genes expressed in the hypothalamus of adult tilapia, Oreochromis mossambicus. Biochem Biophys Res Commun 316: 523-527, 2004.

6. Biswas MK, Chai L, Qiang X and Deng X: Generation, functional analysis and utility of Citrus grandis EST from a flower-derived cDNA library. Mol Biol Rep 39: 7221-7235, 2012.

7. Yoon S, Lee HW, Baek SY, Kim BS, Kim JJ and Lee SA: Upregulation of TrkA neurotrophin receptor expression in the thymic subcapsular, paraseptal, perivascular, and cortical epithelial cells during thymus regeneration. Histochem Cell Biol 119: 55-68, 2003.

8. Lee HW, Kim SM, Shim NR, Bae SK, Jung IG, Kwak JY, Kim BS, Kim JB, Moon JO, Chung JS and Yoon S: Expression of nerve growth factor is upregulated in the rat thymic epithelial cells during thymus regeneration following acute thymic involution. Regul Pept 141: 86-95, 2007.

9. Park HJ, Kim MN, Kim JG, Bae YH, Bae MK, Wee HJ, Kim TW, Kim BS, Kim JB, Bae SK and Yoon S: Up-regulation of VEGF expression by NGF that enhances reparative angiogenesis during thymic regeneration in adult rat. Biochim Biophys Acta 1773: 1462-1472, 2007.

10. Kim YM, Kim HK, Kim HJ, Lee HW, Ju SA, Choi BK, Kwon BS, Kim BS, Kim JB, Lim YT and Yoon S: Expression of 4-1BB and 4-1BBL in thymocytes during thymus regeneration. Exp Mol Med 41: 896-911, 2009.

11. Li A, Ponten F, dos Remedios CG: The interactome of LIM domain proteins: the contributions of LIM domain proteins to heart failure and heart development. Proteomics 12: 203-225, 2012.

12. Nouët Y, Dahan J, Labalette C, Levillayer F, Julien B, Jouvion G, Cairo S, Vives FL, Ribeiro A, Huerre M, Colnot S, Perret C, Van Nhieu JT, Tordjmann T, Buendia MA and Wei Y: The four and a half LIM-only protein 2 regulates liver homeostasis and contributes to carcinogenesis. J Hepatol 57: 1029-1036, 2012.

13. Herblot S, Steff AM, Hugo P, Aplan PD and Hoang T: SCL and LMO1 alter thymocyte differentiation: inhibition of E2A-HEB function and pre-T alpha chain expression. Nat Immunol 1: $138-144,2000$.

14. Kirchner J, Forbush KA and Bevan MJ: Identification and characterization of thymus LIM protein: targeted disruption reduces thymus cellularity. Mol Cell Biol 21: 8592-8604, 2001.

15. Pinto do OP, Kolterud A and Carlsson L: Expression of the LIM-homeobox gene LH2 generates immortalized steel factordependent multipotent hematopoietic precursors. EMBO J 17: 5744-5756, 1998 . 
16. Yamada Y, Warren AJ, Dobson C, Forster A, Pannell R and Rabbitts TH: The T cell leukemia LIM protein Lmo2 is necessary for adult mouse hematopoiesis. Proc Natl Acad Sci USA 95: 3890-3895, 1998.

17. Terano T, Zhong Y, Toyokuni S, Hiai H and Yamada Y: Transcriptional control of fetal liver hematopoiesis: dominant negative effect of the overexpression of the LIM domain mutants of LMO2. Exp Hematol 33: 641-651, 2005.

18. Tao Y, Wang J, Tokusumi T, Gajewski K and Schulz RA: Requirement of the LIM homeodomain transcription factor tailup for normal heart and hematopoietic organ formation in Drosophila melanogaster. Mol Cell Biol 27: 3962-3969, 2007.

19. Zoller Al and Kersh GJ: Estrogen induces thymic atrophy by eliminating early thymic progenitors and inhibiting proliferation of beta-selected thymocytes. J Immunol 176: 7371-7378, 2006

20. Charpentier AH, Bednarek AK, Daniel RL, Hawkins KA Laflin KJ, Gaddis S, MacLeod MC and Aldaz CM: Effects of estrogen on global gene expression: identification of novel targets of estrogen action. Cancer Res 60: 5977-5983, 2000

21. Lee HW, Na YJ, Jung PK, Kim MN, Kim SM, Chung JS, Kim BS Kim JB, Moon JO and Yoon S: Nerve growth factor stimulates proliferation, adhesion and thymopoietic cytokine expression in mouse thymic epithelial cells in vitro. Regul Pept 147: 72-81, 2008

22. Shao Y, Akmentin W, Toledo-Aral JJ, Rosenbaum J, Valdez G, Cabot JB, Hilbush BS and Halegoua S: Pincher, a pinocytic chaperone for nerve growth factor/TrkA signaling endosomes. J Cell Biol 157: 679-691, 2002

23. Valdez G, Akmentin W, Philippidou P, Kuruvilla R, Ginty DD and Halegoua S: Pincher-mediated macroendocytosis underlies retrograde signaling by neurotrophin receptors. J Neurosci 25 5236-5247, 2005

24. Philippidou P, Valdez G, Akmentin W, Bowers WJ, Federoff HJ and Halegoua S: Trk retrograde signaling requires persistent, Pincher-directed endosomes. Proc Natl Acad Sci USA 108 852-857, 2011

25. Martineau Y, Martineau Y, Derry MC, Wang X, Yanagiya A Berlanga JJ, Shyu AB, Imataka H, Gehring K and Sonenberg N: Poly(A)-binding protein-interacting protein 1 binds to eukaryotic translation initiation factor 3 to stimulate translation. Mol Cell Biol 28: 6658-6667, 2008.

26. Khaleghpour K, Svitkin YV, Craig AW, DeMaria CT, Deo RC Burley SK and Sonenberg N: Translational repression by a novel partner of human poly $(\mathrm{A})$ binding protein, Paip2. Mol Cell 7: 205-216, 2001.

27. Karim MM, Svitkin YV, Kahvejian A, De Crescenzo G, CostaMattioli $\mathrm{M}$ and Sonenberg N: A mechanism of translational repression by competition of Paip2 with eIF4G for poly(A) binding protein (PABP) binding. Proc Natl Acad Sci USA 103 9494-9499, 2006.

28. Berlanga JJ, Baass A and Sonenberg N: Regulation of poly(A) binding protein function in translation: characterization of the Paip2 homolog, Paip2B. RNA 12: 1556-1568, 2006.

29. Yanagiya A, Delbes G, Svitkin YV, Robaire B and Sonenberg N The poly(A)-binding protein partner Paip2a controls translation during late spermiogenesis in mice. J Clin Invest 120: 3389-3400, 2010.
30. Chen W, Jin W, Tian H, Sicurello P, Frank M, Orenstein JM and Wahl SM: Requirement for transforming growth factor betal in controlling T cell apoptosis. J Exp Med 194: 439-453, 2001

31. Agui T, Xin X, Cai Y, Shim G, Muramatsu Y, Yamada T, Fujiwara $\mathrm{H}$ and Matsumoto K: Opposite actions of transforming growth factor-beta 1 on the gene expression of atrial natriuretic peptide biological and clearance receptors in a murine thymic stromal cell line. J Biochem 118: 500-507, 1995.

32. Hauri-Hohl MM, Zuklys S, Keller MP, Jeker LT, Barthlott T, Moon AM, Roes J and Holländer GA: TGF-beta signaling in thymic epithelial cells regulates thymic involution and postirradiation reconstitution. Blood 112: 626-634, 2008.

33. Pollok KE, Kim YJ, Zhou Z, Hurtado J, Kim KK, Pickard RT and Kwon BS: Inducible T cell antigen 4-1BB. Analysis of expression and function. J Immunol 150: 771-781, 1993.

34. Takahashi C, Mittler RS and Vella AT: 4-1BB is a bona fide CD8 T cell survival signal. J Immunol 162: 5037-5040, 1999.

35. Tsubota Y, Mizushima H, Hirosaki T, Higashi S, Yasumitsu H and Miyazaki K: Isolation and activity of proteolytic fragment of laminin-5 alpha3 chain. Biochem Biophys Res Commun 278: 614-620, 2000

36. Kim JM, Park WH and Min BM: The PPFLMLLKGSTR motif in globular domain 3 of the human laminin-5 alpha3 chain is crucial for integrin alpha3beta1 binding and cell adhesion. Exp Cell Res 304: 317-327, 2005.

37. Bush LA, Herr JC, Wolkowicz M, Sherman NE, Shore A and Flickinger CJ: A novel asparaginase-like protein is a sperm autoantigen in rats. Mol Reprod Dev 62: 233-247, 2002.

38. Bunpo P, Dudley A, Cundiff JK, Cavener DR, Wek RC and Anthony TG: GCN2 protein kinase is required to activate amino acid deprivation responses in mice treated with the anti-cancer agent L-asparaginase. J Biol Chem 284: 32742-32749, 2009.

39. Bunpo P, Cundiff JK, Reinert RB, Wek RC, Aldrich CJ and Anthony TG: The eIF2 kinase GCN2 is essential for the murine immune system to adapt to amino acid deprivation by asparaginase. J Nutr 140: 2020-2027, 2010

40. Kim EH, Koh EH, Park JY and Lee KU: Adenine nucleotide translocator as a regulator of mitochondrial function: implication in the pathogenesis of metabolic syndrome. Korean Diabetes J 34: 146-153,2010.

41. Jang JY and Lee CE: Mitochondrial adenine nucleotide translocator 3 is regulated by IL-4 and IFN-gamma via STAT-dependent pathways. Cell Immunol 226: 11-19, 2003.

42. Jang JY and Lee CE: IL-4-induced upregulation of adenine nucleotide translocase 3 and its role in Th cell survival from apoptosis. Cell Immunol 241: 14-25, 2006.

43. Crockford D, Turjman N, Allan C and Angel J: Thymosin $\beta 4$ : structure, function, and biological properties supporting current and future clinical applications. Ann NY Acad Sci 1194: 179-189, 2010.

44. Low TL, Hu SK and Goldstein AL: Complete amino acid sequence of bovine thymosin beta 4 : a thymic hormone that induces terminal deoxynucleotidyl transferase activity in thymocyte populations. Proc Natl Acad Sci USA 78: 1162-1166, 1981. 